\title{
Social Media's Perspective on Industry 4.0: A Twitter Analysis
}

\author{
İlker Güven Yilmaz ${ }^{1}$ Doğuş Aygün1, Zuhal Tanrikulu² \\ ${ }^{1}$ Department of Informatics, Istanbul University, Istanbul, Turkey \\ ${ }^{2}$ Department of Management Information Systems, Bogazici University, Istanbul, Turkey \\ Email: ilkerguvenyilmaz@gmail.com,aygundogus@gmail.com,zuhal.tanrikulu@boun.edu.tr
}

How to cite this paper: Yilmaz, I.G., Aygün, D. and Tanrikulu, Z. (2017) Social Media's Perspective on Industry 4.0: A Twitter Analysis. Social Networking, 6, 251-261. https://doi.org/10.4236/sn.2017.64017

Received: July 10, 2017

Accepted: August 12, 2017

Published: August 15, 2017

Copyright (c) 2017 by authors and Scientific Research Publishing Inc. This work is licensed under the Creative Commons Attribution International License (CC BY 4.0).

http://creativecommons.org/licenses/by/4.0/

\begin{abstract}
The development and change that has taken place in the industry recently entered a new phase in parallel with the developments in computer technology. This phase is referred as Industry 4.0. With Industry 4.0, companies are working to take advantage of information technology to increase profitability and productivity. Increasing use of social media in recent years has forced companies to show their presence on those platforms. Social media is a major source of meaningful information for companies because it contains large amounts of data. In this study, the top five companies operating in information technology (IT) research/consulting and the top five companies operating in enterprise resource planning (ERP) field were selected. Conclusions have been made based on the analysis of the tweets related to Industry 4.0.
\end{abstract}

\section{Keywords}

Social Media, Twitter, Text Mining, Industry 4.0

\section{Introduction}

The concept of Industry 4.0 has emerged to express a new phase in industrial transformation. As the name suggests, this concept refers to fourth industrial revolution. The reason behind this definition is the advancement of today's computer technologies, which have started a new era in the industry.

The founder of World Economic Forum, Klaus Schwab [1] stated that having a globally shared view about how technology is changing our lives is necessary, as those changes are so profound they show great promise, but they may also bring great peril. Brettel et al. [2] pointed out that the concept of Industry 4.0 explains changes in the industrial world, however the term is being used in different contexts and does not have a clear definition. Current use of the term is 
insignificant and meaningless in some respects, as there is insufficient information about the concept [3]. Moreover, the over-ambitious marketing of this concept made it even more difficult to understand [4]. Sources referring to Industry 4.0 are repeating the same things in different ways. However, growing use of this terminology can be counted as evidence of industrial development's transition to a new phase [5].

With the Industry 4.0, the industry has entered a new turn in the wake of the emergence of the concept of big data. In today's competitive business environment, companies face the challenges of making rapid decisions about big data for improved productivity. However, many manufacturing systems are not ready to manage big data due to the lack of intelligent analytical tools [6]. In the recent years, there has been increased interest in the potential of big data \& analytics concepts to improve organizational performance and these concepts have started to become very popular in the literature of both management science and information science [7].

In this study, social media analysis was conducted to compare the two different fields in IT sector about their perspective on Industry 4.0. For this purpose, Twitter was chosen as a social media platform as it contains vast amounts of unstructured data. Firstly, existing literature related to Industry 4.0 such as business intelligence \& analytics, decision making, social media and text mining are discussed. Following data collection process, dataset structure and Twitter analysis are explained in method section and finally results of the analysis are shown.

\section{Literature Review}

"Industry 4.0 includes a wide range of concepts, including different perspectives, industries, technologies and areas." [8] The idea behind Industry 4.0 comes from the first three industrial revolutions, which were mechanization, electricity and computer and automation [9]. Future-oriented technologies in the areas of internet technologies and "smart" objects (machines and products) are causing a new fundamental paradigm shift in industrial production [10]. Because of this paradigm shift, some challenges about data management and decision-making have arisen [11] [12]. Industry 4.0 is a "response" to those increasing challenges of computerized decision-making and big data [13].

Industry 4.0 is associated with many concepts such as Embedded Systems, Internet of Things and Cyber-Physical Systems [5] [13]. Many companies, organizations, and universities work on different aspects of Industry 4.0 although there are four requirements as pre-conditions for industrial acceptance, which are; investment protection, stability, data privacy and cybersecurity [4]. For Germany, the aim of the Industry 4.0 project is to prepare for the future of manufacturing of the German industry [14]. In the future vision of production, efficient manufacturing systems are crucial since these systems define scenarios in which products control their own production processes [10].

Cyber-Physical Systems have become quite popular in the literature recently, 
especially in the fields of computer science and manufacturing. Cyber-Physical Systems include intelligent machines, storage systems and production facilities capable of sending and receiving information autonomously, units that can act and control each other independently [15]. Cyber-Physical Systems make huge amounts of raw data important for manufacturing and provide opportunities for real-time management of processes [16].

Bauer et al. [17] concluded that mobile devices and social media are part of Industry 4.0 since the manufacturing environment is leading to real-time transparency, which will make production control, and management processes more flexible. This "digital transformation" can be challenging for the companies however, many companies are already started their journey to transformation since they provide interactive websites, improved customer service and so on [18]. Westerman and McAfee [19] found out that large businesses use embedded systems, mobile analytics and social media to change customer engagement, internal operations and even their business models. "Twitter acquired the social data aggregator Gnip as part of Twitter's strategy to create a new service that integrates social and mobile data with analytics to provide real-time business intelligence." [20]

The business intelligence begins with the extraction of data, depositing in warehouses; then the decision-maker uses decision-support systems to extract data from the data warehouse, and decision maker makes an action plan based on this information [21]. In fact, the aim of business intelligence is making operational data valuable by analysis and to provide the necessary data to decision makers [22]. McAfee and Brynjolfsson [23] found that not every company is data-driven in decision-making, but companies that defined themselves as data-driven in the analyses provided better results in financial and operational issues and on average 5\% more productive than other companies. According to Bi et al. [24] from the data management perspective, the Management Information Systems for the next generation manufacturing enterprises are facing two situations: 1) increased costs due to the complexity of the system and the need for rapid decision-making; 2) waste of time and resources for communications when the data are shared with other units [20]. In addition to this, machine learning algorithms can be used to find out the causes of statistics, trends, and links that the business analytics reveals and through these algorithms patterns can be uncovered [7]. Advanced analytics and artificial intelligence give companies new abilities to draw insights from huge amounts of data [25]. A research conducted by Accenture [26] found out that artificial intelligence has an impact on administration, decision-making and innovation as $86 \%$ of managers say that they need help from intelligent systems when monitoring and reporting.

Business analytics is a layer of services for direct decision-making and is an extension of the "information systems" which is a fundamental interdisciplinary research area [27]. Business intelligence allows managers to make sensible decisions about the management of the company. Decisions made with business in- 
telligence create processes that are more efficient; thus, they create a competitive advantage [28]. In the recent past, manufacturing companies have been late for adopting advanced data warehousing and business intelligence solutions; but they have attempted to use business intelligence in order to reduce cycle time and waste in manufacturing [29]. Business intelligence and business analytics serve the same purpose but their definitions are different. Business intelligence focuses on reporting while business analytics is statistical and future-oriented. These concepts are elements of a larger concept named "big data" [30]. The emerge of social networks such as Twitter and Facebook, plus the developments in mobile connectivity such as smart phones and tablet devices have resulted an explosion in data which now requires business analytics to take full advantage of it [18]. There are various data formats in social media platforms such as texts, videos, images so on. For this reason, mining data from social media has become extremely important.

Twitter is a social media platform and a microblog founded in 2006 [31]. In Twitter, information spreads in the form of Retweets [32]. Information shared in short texts in microblogs and this makes microblogs important for text mining [33]. Additionally, microblogs are valuable source of people's opinions since many people use those platforms [34]. On Twitter, users connect through \#hashtags on specific topic(s).

\section{Data Collection and Data Pre-Processing}

Five companies operating in the field of IT research \& consulting and five companies in ERP were selected. Selected IT research companies are Gartner, IBM, Forrester, Thomson Reuters and Nielsen Media. Selected ERP companies are SAP, ORACLE, Microsoft, Infor and Epicor. Separate data sets for both fields were created and tweets from the official twitter accounts of companies were collected.

\subsection{Twitter Accounts}

The official Twitter accounts of the companies that make up the datasets are given in Table 1.

\subsection{Data Collection}

The Twitter API service [35] was used to create the datasets. As shown in Table 1 , a total number of 10 twitter accounts were used. Tweets were obtained separately from each account and depending of the field of companies tweets were collected in two datasets independent from each other. In dataset, each row contains 16 properties, which are text, favorited, favorite Count, replyToSN, created, truncated, re-plyToSID, id, replyToUID, status Source, screen Name, retweet Count, is Retweet, re-tweeted, longitude, and latitude. An example is shown in Figure 1.

Table 2 shows the number of tweets in each dataset and the date range that 
Table 1. Twitter accounts.

\begin{tabular}{ccc}
\hline & Account Details & \\
\hline Field & Company Name & Twitter Account \\
\hline \multirow{2}{*}{ Research \& Consulting } & Gartner & @Gartner_inc \\
& IBM & @IBM \\
& Forrester & @forrester \\
& Thomson Reuters & @thomsonreuters \\
& Nielsen Media & @Nielsen \\
& SAP & @SAP \\
& ORACLE & @Oracle \\
Enterprise Resource Planning (ERP) & Microsoft & @msftdynamics365 \\
& Infor & @Infor \\
& Epicor & @Epicor \\
\hline
\end{tabular}

Table 2. Details of datasets.

\begin{tabular}{cccc}
\hline Field & Account & $\begin{array}{c}\text { Date Interval of } \\
\text { Created Tweets }\end{array}$ & Count of Tweets \\
\hline & @Gartner_inc & $20.05 .2017-26.01 .2017$ & 396 \\
Research \& & @IBM & $19.05 .2017-06.04 .2017$ & 75 \\
Consulting & @forrester & $19.05 .2017-26.09 .2016$ & 547 \\
& @thomsonreuters & $19.05 .2017-20.04 .2017$ & 104 \\
& @Nielsen & $19.05 .2017-24.09 .2016$ & 495 \\
Enterprise & @SAP & $10.03 .2016-20.05 .2017$ & 1666 \\
Resource & @Oracle & $19.05 .2017-01.05 .2017$ & 74 \\
Planning (ERP) & @ & $19.05 .2017-04.11 .2016$ & 236 \\
& @Infor & $19.05 .2017-24.12 .2016$ & 181 \\
& @Epicor & $19.05 .2017-15.05 .2016$ & 216 \\
\hline
\end{tabular}

\begin{tabular}{|c|c|c|c|c|c|}
\hline & text & favorited & favoriteCount & replyToSN & created \\
\hline 1 & "\#Oracle is committed to tennis," says @MarkVHurd... & FALSE & 47 & NA & $2017-05-1622: 30: 22$ \\
\hline 2 & "Anything less than real-time is wasted time" - do you... & FALSE & 18 & NA & $2016-07-2515: 10: 01$ \\
\hline 3 & "Be at the right place at the right time" isn't just a s... & FALSE & 6 & NA & $2016-08-1819: 31: 01$ \\
\hline 4 & "Buyers are beginning to favor convenience \&amp; e... & FALSE & 5 & NA & $2017-01-2719: 00: 05$ \\
\hline 5 & "Cloud productivity boom"- Resources that used to b... & FALSE & 3 & NA & $2017-05-0323: 14: 14$ \\
\hline
\end{tabular}

Figure 1. Example dataset for ERP companies.

tweets were posted. The creation date of each timeline for all accounts are different which is why the user Timeline function in twitter $\mathrm{R}$ package gives different date interval of created tweets for each timeline. Twitter allows obtaining a maximum number of 3200 tweets for each twitter account, which causes a limitation in this study. Furthermore, the Twitter API service does not allow obtaining tweets on a specific date range [36]. For this reason, the date range and number of tweets in datasets are different from each other. 


\subsection{Data Preparation}

The punctuation marks, numbers, links, blanks, pauses and irrelevant words were cleared from the tweets before they were analyzed in the dataset, as those would affect the results of this study.

R packages such as httr, devtools, twitteR, base64enc, xlsx, tm, sentiment 140, sentiment, topic models and ggplot2 were used in the analysis [37]-[46].

\section{Method}

In this study, text-mining analysis is performed by using $\mathrm{R}$ programming language [47]. R Studio software is used for all analysis [48]. Tweets were obtained from the official Twitter accounts of the specified companies and they were clustered in separate dataset according to business fields of the companies. As stated in the data preparation step, various clearing procedures have been applied to tweets to ensure that all results are reliable. After this phase, word frequencies were obtained and depending on the field of the selected companies, frequently used words were found to create a list of top frequent words for each field. Besides, the words related to (associations) Industry 4.0 were examined.

The words presented in Table 3 were searched in the clustered tweets, which are clustered according to the business fields. Then, the tweets which are related with the words presented in Table 3 were transferred to two separate datasets for each field.

"In machine learning and natural language processing topic models are generative models which provide a probabilistic framework for the term frequency occurrences in documents in a given corpus." [45] From this point of view, topic modelling was performed on the transferred tweets. Furthermore, Dickinson and $\mathrm{Hu}[49]$ stated that sentiment analysis focuses on opinions of speakers on a particular topic. Therefore, sentiment analysis was performed on the transferred tweets to reveal the polarity of the tweets related to Industry 4.0.

\section{Findings}

\subsection{Top Frequent Words}

The word frequencies in the tweets of both fields that contain words related to Industry 4.0, which is given in Table 3 , are identified and the five most frequently used words are presented in Table 4.

\subsection{Topic Modelling}

The topic modelling was performed with tweets that contain words related to

Table 3. List of words related with Industry 4.0.

$$
\text { Words }
$$

Industry 40, industry 40, Industry 4.0, Industry 4.0, big data, bigdata, machine learning, machinelearning 
Industry 4.0 in each field. The topic models for each field are presented in Figure 2 and Figure 3.

\subsection{Sentiment Analysis}

The tweets for each field are classified as positive, negative and neutral and the results of the sentiment analysis are presented in Table 5.

As shown in Table 5, ERP companies shared more neutral tweets than research and consulting companies. The counts of negative tweets for both field are equal.

\section{Discussion and Conclusions}

The obtained results show that ERP companies used the words "machine", "learning", "data", "big" and "learn" while tweeting about Industry 4.0. In addition to that, the words "news", "data", "big", "real" and "separate" came to forefront in the tweets that research \& consulting companies tweeted about Industry 4.0. These results show that the both fields are aware of the "big data" concept, which was discussed in the literature review of this study.

According to the results of the sentiment analysis, companies often share tweets about Industry 4.0 with neutral polarity. This shows that shared tweets have no positive or negative effect on the users.

This study is limited to total 10 companies selected from the IT sector in the fields of research \& consulting and ERP. Furthermore, only Twitter is used as a social platform and limited data could be obtained. Future studies can be done

Table 4. Top 5 frequent words.

\begin{tabular}{ccc}
\hline Field & Term & Frequency \\
\hline Research \& Consulting & news & 5 \\
& data & 4 \\
Enterprise Resource Planning (ERP) & big & 3 \\
& real & 3 \\
& separate & 3 \\
& machine & 22 \\
& learning & 20 \\
& data & 15 \\
& big & 12 \\
\hline
\end{tabular}

Table 5. Results of sentiment analysis.

\begin{tabular}{cccc}
\hline \multirow{2}{*}{ Field } & \multicolumn{3}{c}{ Polarity } \\
\cline { 2 - 4 } & Positive & Negative & Neutral \\
\hline Research \& Consulting & - & 1 & 10 \\
ERP & 1 & 1 & 44 \\
\hline
\end{tabular}




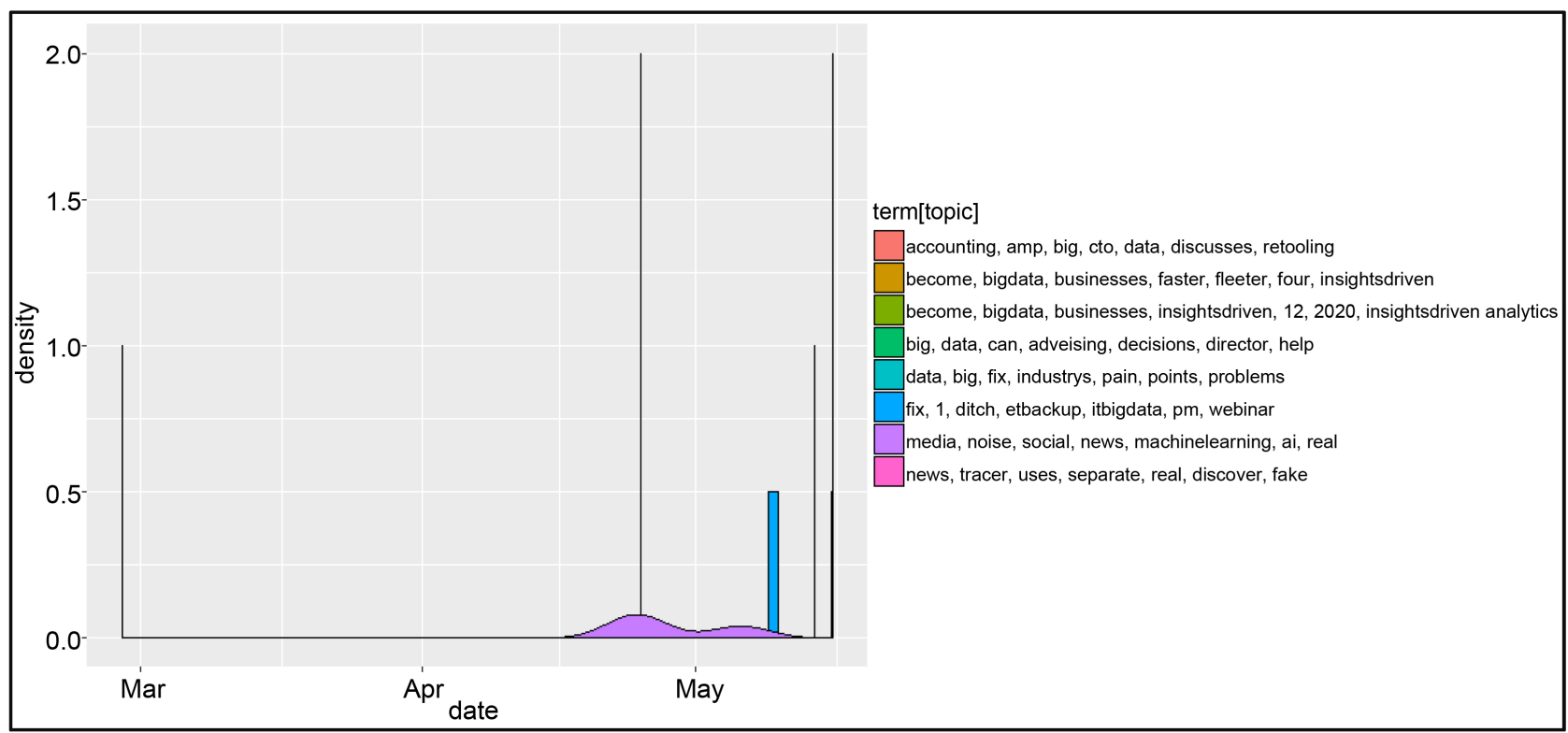

Figure 2. Topic model for research \& consulting companies.

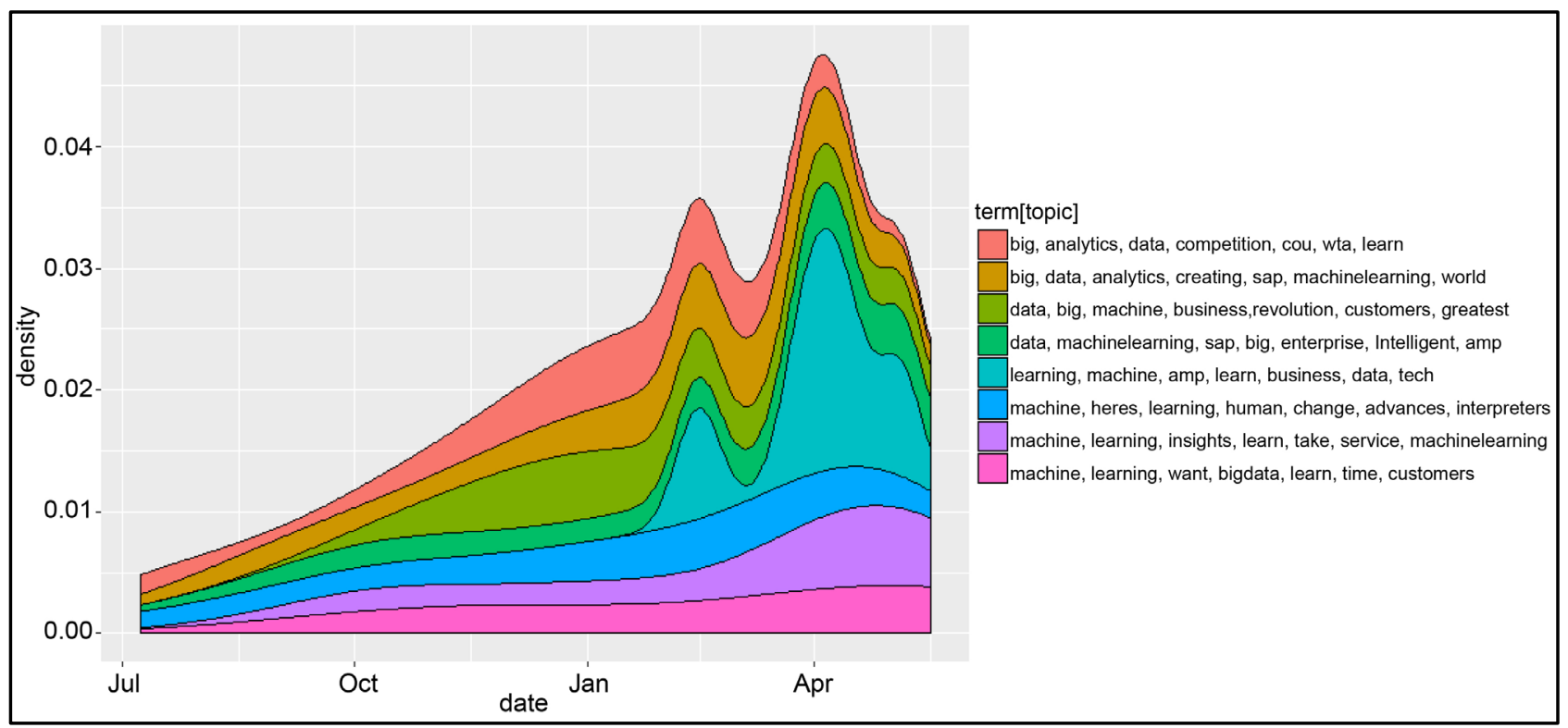

Figure 3. Topic model for ERP companies.

on different social platforms, on different number of companies about Industry 4.0.

\section{References}

[1] Schwab, K. (2017) The Fourth Industrial Revolution. Crown Publishing Group, New York.

[2] Brettel, M., Friederichsen, N., Keller, M. and Rosenberg, M. (2014) How Virtualization, Decentralization and Network Building Change the Man-Ufacturing Landscape: An Industry 4.0 Perspective. International Journal of Mechanical, Industrial Science and Engineering, 8, 37-44. 
[3] Rodriguez, K. (2017) Have We Reached the Fourth Industrial Revolution? https://execed.economist.com/career-advice/industry-trends/have-we-reached-fourt h-industrial-revolution

[4] Drath, R. and Horch, A. (2014) Industrie 4.0: Hit or Hype? IEEE Industrial Electronics Magazine, 8, 56-58. https://doi.org/10.1109/MIE.2014.2312079

[5] Frederick, D.E. (2016) Libraries, Data and the Fourth Industrial Revolution (Data Deluge Column). Library Hi Tech News, 33, 9-12.

https://doi.org/10.1108/LHTN-05-2016-0025

[6] Lee, J., Kao, H.A. and Yang, S. (2014) Service Innovation and Smart Analytics for Industry 4.0 and Big Data Environment. Procedia CIRP, 16, 3-8. https://doi.org/10.1016/j.procir.2014.02.001

[7] Sharma, R., Mithas, S. and Kankanhalli, A. (2014) Transforming Decision-Making Processes: A Research Agenda for Understanding the Impact of Business Analytics on Organisations. European Journal of Information Systems, 23, 433-441. https://doi.org/10.1057/ejis.2014.17

[8] Kagermann, H., Anderl, R., Gausemeier, J., Schuh, G. and Wahlster, W. (2016) Understanding of Industrie 4.0. In: Kagermann, H., Anderl, R., Gausemeier, J., Schuh, G. and Wahlster, W., Eds., Industrie 4.0 in a Global Context. Strategies for Cooperating with International Partners, Herbert Utz Verlag, New York, 19-23.

[9] Weyer, S., Schmitt, M., Ohmer, M. and Gorecky, D. (2015) Towards Industry 4.0Standardization as the Crucial Challenge for Highly Modular, Multi-Vendor Production Systems. IFAC-PapersOnLine, 48, 579-584.

https://doi.org/10.1016/j.ifacol.2015.06.143

[10] Lasi, H., Fettke, P., Kemper, H.G., Feld, T. and Hoffmann, M. (2014) Industry 4.0. Business \& Information Systems Engineering, 6, 239-242.

https://doi.org/10.1007/s12599-014-0334-4

[11] Yin, S. and Kaynak, O. (2015) Big Data for Modern Industry: Challenges and Trends [Point of View]. Proceedings of the IEEE, 103, 143-146. https://doi.org/10.1109/JPROC.2015.2388958

[12] Yi, X., Liu, F., Liu, J. and Jin, H. (2014) Building a Network Highway for Big Data: Architecture and Challenges. IEEE Network, 28, 5-13. https://doi.org/10.1109/MNET.2014.6863125

[13] Saldivar, A.A.F., Li, Y., Chen, W., Zhan, Z., Zhang, J. and Chen, L.Y. (2015) Industry 4.0 with Cyber-Physical İntegration: A Design and Manufacture Perspective. Proceedings of 21 st International Conference on Automation and Computing ICAC, Glasgow, 11-12 September 2015, 1-6.

https://doi.org/10.1109/IConAC.2015.7313954

[14] Bundesministerium für Bildung und Forschung (2017) Industrie 4.0. https://www.bmbf.de/de/zukunftsprojekt-industrie-4-0-848.html

[15] Hermann, M., Pentek, T. and Otto, B. (2016) Design Principles for Industrie 4.0 Scenarios. Proceedings of 49 th Hawaii International Conference on System Sciences HICSS, Koloa, 5-8 January 2016, 3928-3937. https://doi.org/10.1109/HICSS.2016.488

[16] Baars, H., Felden, C., Gluchowski, P., Hilbert, A., Kemper, H.G. and Olbrich, S. (2014) Shaping the Next Incarnation of Business Intelligence. Business \& Information Systems Engineering, 6, 11-16. https://doi.org/10.1007/s12599-013-0307-z

[17] Bauer, W., Hämmerle, M., Schlund, S. and Vocke, C. (2015) Transforming to a Hyper-Connected Society and Economy-Towards an "Industry 4.0." Procedia Manufacturing, 3, 417-424. https://doi.org/10.1016/j.promfg.2015.07.200 
[18] Berman, S.J. (2012) Digital Transformation: Opportunities to Create New Business Models. Strategy \& Leadership, 40, 16-24. https://doi.org/10.1108/10878571211209314

[19] Westerman, G. and McAfee, A. (2012) The Digital Advantage: How Digital Leaders Outperform Their Peers in Every Industry. http://ide.mit.edu/sites/default/files/publications/TheDigitalAdvantage.pdf

[20] Kane, G.C., Palmer, D., Phillips, A.N., Kiron, D. and Buckley, N. (2015) Strategy, not Technology, Drives Digital Transformation: Becoming a Digitally Mature Enterprise. http://sloanreview.mit.edu/projects/strategy-drives-digital-transformation/

[21] Ştefan, M.D. (2009) Improving the Quality of the Decision Making by Using Business Intelligence Solutions. Annals of the University of Oradea, Economic Science Series, 18, 996-1000.

[22] Cross, C. (2016) The Big Data Analytics Revolution-How Big Data Has Changed Business Intelligence.

http://blog.westmonroepartners.com/big-data-analytics-revolution-big-data-change d-business-intelligence/

[23] McAfee, A. and Brynjolfsson, E. (2012) Big Data: The Management Revolution. https://hbr.org/2012/10/big-data-the-management-revolution

[24] Bi, Z., Xu, L.D. and Wang, C. (2014) Internet of Things for Enterprise Systems of Modern Manufacturing. IEEE Transactions on Industrial Informatics, 10, 15371546. https://doi.org/10.1109/TII.2014.2300338

[25] Hartmann, B., King, W.P. and Narayanan, S. (2015) Digital Manufacturing: The Revolution Will Be Virtualized.

http://www.gospi.fr/IMG/pdf/digital_manufacturing_the_revolution_will_be_virtua lized.pdf

[26] Accenture (2016) The Promise of Artificial Intelligence: Redefining Management in the Workforce of the Future.

https://www.accenture.com/us-en/insight-promise-artificial-intelligence

[27] Goes, P.B. (2014) Big Data and IS Research. MIS Quarterly, 38, 3-8.

[28] Foley, É. and Guillemette, M.G. (2012) What Is Business Intelligence? In: Herschel, R.T., Ed., Organizational Applications of Business Intelligence Management. Emerging Trends, IGI Global, Hershey, 52-75. https://doi.org/10.4018/978-1-4666-0279-3.ch005

[29] Stackowiak, R., Rayman, J. and Greenwald, R. (2007) Oracle Data Warehousing and Business Intelligence Solutions. Wiley Publishing, Inc., Indianapolis, Indiana.

[30] Chen, H., Chiang, R.H. and Storey, V.C. (2012) Business Intelligence and Analytics: From Big Data to Big Impact. MIS Quarterly, 36, 1165-1188.

[31] Java, A., Song, X., Finin, T. and Tseng, B. (2007) Why We Twitter: Understanding Microblogging Usage and Communities. Proceedings of the Joint 9 th WEBKDD and 1 st SNA-KDD Workshop, 2007, 56-65.

[32] Zaman, T.R., Herbrich, R., Van Gael, J. and Stern, D. (2010) Predicting Information Spreading in Twitter. Proceedings of the Workshop on Computational Social Science and the Wisdom of Crowds NIPS, Whistler, 10 December 2010, 1759917601.

[33] Hu, X. and Liu, H. (2012) Text Analytics in Social Media. In: Aggarwal, C.C. and Zhai, C., Eds., Mining Text Data, Springer Science \& Business Media, LLC, New York, 385-414. https://doi.org/10.1007/978-1-4614-3223-4_12 
[34] Pak, A. and Paroubek, P. (2010) Twitter as a Corpus for Sentiment Analysis and Opinion Mining. Proceedings of the International Conference on Language Resources and Evaluation LREC, Valletta, 17-23 May 2010, 1320-1326.

[35] Twitter Inc. (2017) REST APIs-Twitter Developers. https://dev.twitter.com/rest/public

[36] Twitter Developers Forums (2011) How We Can Retrive the Tweets for User for Specific Time Span (Start Date and End Date)?-Twitter Developers.

https://twittercommunity.com/t/how-we-can-retrive-the-tweets-for-user-for-specifi c-time-span-start-date-and-end-date/7290

[37] Wickham, H. (2016) Httr: Tools for Working with URLs and HTTP (Version 1.2.1). https://CRAN.R-project.org/package=httr

[38] Wickham, H. and Chang, W. (2016) Devtools: Tools to Make Developing R Packages Easier (Version 1.12.0). https://CRAN.R-project.org/package=devtools

[39] Gentry, J. (2015) TwitteR: R Based Twitter Client (Version 1.1.9). https://CRAN.R-project.org/package=twitteR

[40] Urbanek, S. (2015) Base64enc: Tools for Base64 Encoding (Version 0.1-3). https://CRAN.R-project.org/package=base64enc

[41] Dragulescu, A.A. (2014) Xlsx: Read, Write, Format Excel 2007 and Excel 97/2000/ $\mathrm{XP} / 2003$ Files (Version 0.5.7) https://CRAN.R-project.org/package=xlsx

[42] Feinerer, I. and Hornik, K. (2017) Tm: Text Mining Package (Version 0.7-1). https://CRAN.R-project.org/package $=$ tm

[43] Okugami, C. (2013) Sentiment140: R Package for Twitter Sentiment Text Analysis (Version 1.0). https://github.com/okugami79/sentiment140

[44] Okugami, C. (2013) Sentiment: NLP Sentiment Analysis Tool in R (Version 1.0).

[45] Hornik, K. and Grün, B. (2011) Topicmodels: An R Package for Fitting Topic Models. Journal of Statistical Software, 40, 1-30. https://doi.org/10.18637/jss.v040.i13

[46] Wickham, H. (2009) Ggplot2: Elegant Graphics for Data Analysis. 2nd Edition, Springer, New York. https://doi.org/10.1007/978-0-387-98141-3

[47] R Development Core Team (2016) R: A Language and Environment for Statistical Computing. R Foundation for Statistical Computing, Vienna. https://www.R-project.org/

[48] RStudio Team (2017) RStudio: Integrated Development Environment for R (Version 1.0.136). RStudio Inc., Boston. https://www.rstudio.com/

[49] Dickinson, B. and Hu, W. (2015) Sentiment Analysis of Investor Opinions on Twitter. Social Networking, 4, 62-71. https://doi.org/10.4236/sn.2015.43008 